Jurnal Ilmu Keolahragaan Vol. 17 (2), Juli-Desember 2018: 1 - 5

\title{
PENGARUH PENDIDIKAN DI LUAR KELAS (OUTDOOR EDUCATION) TERHADAP PENGEMBANGAN KARAKTER SISWA
}

\author{
Muhammad Chairad ${ }^{1}$ Bangun Setia Hasibuan ${ }^{2}$ Zen Fadli ${ }^{3}$ Iwan Saputra ${ }^{4}$
}

\begin{abstract}
Abstrak : Tujuan penelitian ini adalah untuk menjawab apakah penerapan pendidikan di luar kelas mampu memberikan pengaruh keterampilan sosial (karakter) para siswa. jika tidak penelitian ini juga berusaha untuk menjawab apakah ada perubahan yang terjadi setelah dilakukan pembelajaran dan untuk dalam jangka waktu tertentu pada siswa Sekolah Menengah Pertama (SMP). Pengembangan karakter adalah suatu hal yang sangat urgen bagi siswa yang harus dilakukan secara terintegrasi dalam proses pembelajaran sesuai dengan tujuan pendidikan Nasional yang telah dituangkan dalam kurikulum nasional. Penelitian deskriptif ini menggunakan desain quasi eksperimen. Data penelitian ini dikumpulkan melalui kuesioner. Tehnik analisis data yang digunakan dalam penelitian ini menggunakan uji-t, untuk mengetahui pengaruh pendidikan di luar kelas terhadap pengembangan keterampilan sosial (karakter).
\end{abstract}

Kata Kunci : Karakter, Pendidikan diluar kelas

\section{PENDAHULUAN}

Pendidikan karakter sudah menjadi topik yang banyak menjadi sorotan dan diperbincangkan serta dikaji dalam berbagai pertemuan ilmiah. Ada anggapan bahwa permasalahan hidup yang saat ini banyak muncul dan cukup kompleks sebagai akibat rendah atau minimnya pendidikan karakter di lembaga-lembaga pendidikan termasuk di Sekolah menengah Pertama(SMP). Munculnya kebutuhan akan pendidikan karakter mengundang sejumlah pertanyaan. Di antaranya, pendidikan karakter seperti apa yang diperlukan masyarakat dan bangsa yang saat ini dibelit berbagai persoalan? Strategi apa yang dapat digunakan untuk menanamkan dasar-dasar pengembangan karakter pada anak usia remaja yang sedang duduk di Sekolah Menengah Pertama (SMP)? Apakah dengan pendidikan di luar kelas yang nuansanya bermain dapat mengembangkan karakter anak?

Pendidikan di luar kelas (outdoor education) adalah pendidikan holistik yang membantu perkembangan pada masa remaja, termasuk kemampuan akademik, fisik, emosional, sosial dan psikologi (Gray dan Parusco 1993; Marsh \& Richards 1988; Davidson tahun 2001; Hattie 1997). Hal ini mampu memberikan kesempatan peserta didik untuk menerapkan pengetahuan dan keterampilan yang dikuasai, terutama dalam situasi kehidupan nyata dan meningkatkan pemahaman tentang hubungan antara manusia dan lingkungan (Lugg 1999). Implementasi pendidikan di luar kelas pada kurikulum sekolah menjadi sangat berharga untuk membantu pengajaran dan pembelajaran pendidikan formal di dalam kelas (Henderson \& Barnett, 2001).

Pendidikan Jasmani,olahraga dan kesehatan yang dilakukan di Sekolah Menengah Pertama (SMP) saat ini telah menekankan kegiatan belajar di luar ruangan sebagai unit pembelajaran yang dilakukan oleh seluruh peserta didik. Namun pelaksanaan program ini

\footnotetext{
${ }^{1}$ Penulis adalah Staf Edukatif Fakultas Ilmu Keolahragaan UNIMED

${ }^{2}$ Penulis adalah Staf Edukatif Fakultas Ilmu Keolahragaan UNIMED

${ }^{3}$ Penulis adalah Staf Edukatif Fakultas Ilmu Keolahragaan UNIMED

${ }^{4}$ Penulis adalah Staf Edukatif Fakultas Ilmu Keolahragaan UNIMED
} 
Muhammad Chairad, Bangun Setia Hasibuan, Zen Fadli, Iwan Saputra : Pengaruh Pendidikan Di Luar Kelas (Outdoor Education) Terhadap Pengembangan Karakter Siswa

cenderung lambat dan tidak diberikan prioritas dalam kurikulum sekolah. Guru Jasmani,olahraga dan kesehatan cenderung bermalas-malasan tanpa memikirkan akibat yang timbul terhadap siswanya. Guru menganggap enteng mata pelajaran ini.

Oleh karena itu harus lebih ditekankan kepada guru agar lebih sesrius dan bertanggung jawab dalam mendidik. Karena, masa depan siswa tersebut sedikit banyak berada ditangan gurunya.

\section{METODE}

Jenis penelitian ini menggunakan metode penelitian eksperimen semu. Dalam penelitian ini, sampel yang telah diambil dikelompokkan menjadi dua yaitu kelompok eksperimen dan kelompok kontrol. Adapun design penelitian tampak pada tabel di bawah ini.

Tabel Desain Penelitian

\begin{tabular}{|c|c|c|c|c|}
\hline Tes Awal & Kelompok & Aktifitas & Perlakukan & Tes Akhir \\
\hline \multirow{4}{*}{$\begin{array}{l}\text { Keterampi-lan } \\
\text { Sosial } \\
\text { (karakter) }\end{array}$} & \multirow{3}{*}{ Eksperimen } & \multirow{3}{*}{$\begin{array}{l}\text { Pendidikan } \\
\text { diluar kelas }\end{array}$} & - low risk & \multirow{4}{*}{$\begin{array}{l}\text { Keterampi-lan } \\
\text { sosial (karakter) }\end{array}$} \\
\hline & & & $\begin{array}{l}\text { - low-to high } \\
\text { risk } \\
\text { activities }\end{array}$ & \\
\hline & & & $\begin{array}{l}\text { - high-to low } \\
\text { risk activities }\end{array}$ & \\
\hline & Kontrol & Penjas & Konvensional & \\
\hline
\end{tabular}

Teknik pengumpulan data pada penelitian adalah dengan memberikan angket kepada siswa sebelum dan setelah pembelajaran. Dalam pengumpulan data, peneliti menggunakan skala keterampilan sosial siswa (skala Linkert) Dalam penelitian ini pernyataan sikap responden dibuat dalam bentuk pernyataan yang berupa Sangat Setuju (SS), Setuju (S), Ragu-ragu (RR), Tidak Setuju (TS), dan Sangat Tidak Setuju (STS). Setiap jawaban tersebut memiliki skor tersendiri sesuai dengan positif atau negatifnya item itu. Sebuah item postitif skor tiap pilihannya adalah $\mathrm{STS}=5, \mathrm{~S}=4, \mathrm{RR}=3, \mathrm{TS}=2$, dan $\mathrm{STS}=1$.

Setelah data terkumpul, maka dilakukan analisis data dengan:

1. Edit, yaitu kegiatan memeriksa dan meneliti kembali data yang diperoleh dari hasil kuesioner dan wawancara, untuk mengetahui apakah data yang ada sudah cukup dan lengkap ataukah perlu ada pembetulan.

2. Koding, yaitu kegiatan melakukan klasifikasi data dari jawaban responden dengan memberikan kode/simbol serta skor menurut kriteria yang ada. Jawaban setiap item instrumen tersebut menggunakan skala Likert dalam bentuk pilihan. Skala Likert digunakan untuk mengukur sikap, pendapat dan persepsi seseorang atau sekelompok tentang fenomena sosial (Sugiyono, 2001: 73-74). Untuk setiap item pernyataan diberi skor satu sampai dengan lima dari hasil yang terendah sampai yang tertinggi.

3. Tabulasi, yaitu kegiatan melakukan pengolahan data ke dalam bentuk table dengan memproses hitung frekuensi dari masing-masing kategori, baik secara manual maupun dengan bantuan komputer.

4. Untuk melihat peningkatan keterampilan sosial siswa setiap kelompoknya maka dilakukan dengan uji N-Gain. Untuk menghitung $N$-Gain digunakan rumus yaitu: 
Jurnal Ilmu Keolahragaan Vol. 17 (2), Juli-Desember 2018: 1 - 5

$$
\mathrm{N}-\text { Gain }=\frac{\text { Nilai akhir }- \text { Nilai awal }}{\text { Nilai Maksimum - Nilai awal }}
$$

Kriteria interpretasi indeks $\mathrm{N}$-Gain yang dikemukakan oleh Hake yakni g $>0,7$ (indeks gain tinggi), 0,3<g $<0,7$ (indeks gain sedang) dan $\mathrm{g}<0,3$ (indeks gain rendah).

5. Untuk melihat perbedaan antara kelas ekperimen dengan kelas kontrol dengan uji-t.

HASIL

Hasil dari penelitian ini akan dijelaskan pada bagian ini. Di awal penelitian, peneliti melakukan pengambilan sampel secara acak. Maka terpilih 62 siswa sebagai sampel. Sampel tersebut dibagi menjadi dua kelompok yaitu kelompok kelas kontrol (X) dan kelas eksperimen (Y). Kelompok kelas kontrol (X) berjumlah 31 siswa, dan kelompok kelas eksperimen berjumlah 31 siswa juga.

Instrumen pada penelitian ini adalah angket. Pengukuran angket dengan menggunakan skala Likert. Angket telah divalidasi oleh validator yang berkompeten dibidangnya, yaitu oleh seorang dosen bidang konseling di Fakultas Ilmu Pendidikan Universitas Negeri Medan. Angket terdiri dari 40 pernyataan positif dan negatif yang merupakan pengembangan dari 4 indikator keterampilan sosial yaitu mengajukan pertanyaan, memberikan ide/pendapat, menjadi pendengar yang baik dan dapat bekerja sama.

Selanjutnya peneliti memberikan angket keterampilan sosial awal sebelum pembelajaran dimulai kepada kedua kelompok tersebut. Hasil dari angket tersebut menunjukkan bahwa kedua kelompok sampel tersebut belum memiliki keterampilan sosial yang baik. Hal ini dapat dilihat dari nilai rata-rata persentasi angket keterampilan sosial yang telah diberikan kepada siswa. Pada kelas kontrol dan kelas eksperimen, nilai rata-rata keterampilan sosialnya jika dibulatkan sama yaitu sebesar $63 \%$.

\section{PEMBAHASAN}

Dari data awa, tidak ada perbedaan keterampilan sosial siswa yang terlalu besar antara kelas kontrol dan kelas eksperimen. Jumlah skor keterampilan sosial siswa di kelas kontrol sebesar 3912 dan rata-rata persentasinya 63,1\%. Tidak jauh berbeda, total skor keterapilan sosial di kelas eksperimen sebesar 3929 dengan rata-rata persentasinya 63, 3\%.

Kemudian tahap penelitian dilanjutkan dengan pemberian perlakuan terhadap kedua sampel. Untuk kelas kontrol diberikan perlakuan pembelajaran seperti biasanya, yaitu pembelajaran di dalam kelas. Sedangkan pada kelas ekperimen diberikan perlakuan pembelajaran berbeda dari kelas kontrol, yaitu melakukan aktifitas pendidikan di luar kelas. Aktifitas ini dilakukan sebanyak 3kali pertemuan. Setiap pertemuan dilakukan selama 3 JP. Pada aktifitas dipertemuan pertama melakukan aktifitas Low risk, pada pertemuan kedua melakukan aktifitas Low risk- to High risk dan pada pertemuan ketiga melakukan aktifitas High risk -to Low risk.

Pada pertemuan ketiga, siswa diberikan kembali angket keterampilan sosial seperti di awal pertemuan. Tujuannya adalah untuk melihat sejauh mana perubahan keterampilan sosial siswa setelah diberikan aktifitas di luar kelas. Hasilnya adalah sebagai berikut. Dari persentasi hasil angket akhir keterampilan sosial dapat dilihat terjadi perbedaan antara hasil keterampilan sosial di kelas kontrol dengan yang ada di kelas eksperimen. Pada kelas kontrol total jumlah skor keterampilan sosialnya sebesar 5282 sedangkan pada kelas eksperimen sebesar 5588. Persentasi rata-rata di kelas kontrol 85,2\% sedangkan pada kelas eksperimen $90,1 \%$. Artinya terdapat perbedaan kemampuan keterampilan sosial sebanyak $5 \%$.

Selanjutnya dari data yang ada dianalisis untuk melihat peningkatan keterampilan sosial siswa dengan mencari nilai N-Gainnya. Dan diperoleh hasil jika rata-rata nilai N-Gain pada kelas kontrol di sesuaikan dengan tabel Kriteria Indeks N-Gain, maka hasil yang 
Muhammad Chairad, Bangun Setia Hasibuan, Zen Fadli, Iwan Saputra : Pengaruh Pendidikan Di Luar Kelas (Outdoor Education) Terhadap Pengembangan Karakter Siswa

diperoleh adalaha berada di kategori sedang. Sedangkan untuk kelas eksperimen menunjukkan bahwa rata-rata N-Gainnya berada pada kategori tinggi. Hal ini menjelaskan bahwa peningkatan keterampilan sosial siswa lebih tinggi pada kelas eksperimen dibandingkan dengan kelas eksperimen.

Selanjutnya melihat bagaimana penerapan pendidikan di luar kelas mampu memberikan pengaruh keterampilan sosial (karakter) para siswa. Hasilnya, data diperoleh $t_{\text {hitung }}-11,11$ dengan $\mathrm{df}=58$ maka diperoleh $\mathrm{t}$ table $=1,67$ untuk taraf kesalah $5 \%$ maka dengan demikian $\mathrm{t}$ hasil hitung jatuh di daerah penerimaan hipotesis H0. Artinya keterampilan sosial siswa yang menerima pembelajaran diluar kelas lebih baik dari siswa yang belajar di dalam kelas.

Kesimpulannya adalah dapat dikatakan terjadi pengaruh yang signifikan antara kelas yang diberikan aktifitas di luar kelas dengan yang tidak melakukan aktifitas di luar kelas. Keterampilan siswa lebih tinggi yang melakukan aktifitas di luar kelas.

\section{KESIMPULAN DAN SARAN}

Hasil dari penelitian ini memiliki kesimpulan bahwa melalui penerapan pendidikan di luar kelas dapat mempengaruhi pengembangan keterampilan sosial (karakter) pada siswa. Hal ini dapat dilihat dari hasil perubahan yang terjadi di kelas kontrol dan eksperimen. Saran terhadap peneliti selanjutnya adalah agar dapat mengembangkan penelitian ini lebih luas.

\section{DAFTAR PUSTAKA}

Aip Syarifuddin dan Muhadi. (1992). Pendidikan Jasmani dan Kesehatan. Jakarta: Depdikbud.

Andersen, L. 1995. Creating positive change through an integrated outdoor adventure program. Therapeutic-Recreation-Journal. 31(4): 214-229

Ancok Djamaluddin, 2003. Outbound Manajement Training. Aplikasi Ilmu dalam Pengembangan Manajemen. Yogyakarta ; Pusat Outbound H-Read UII.

Boss, J.A. 1999.Outdoor education and the development of civic responsibility. Charleston, WV: ERIC Clearinghouse ED425051.

Burnard, P. 1991. Experiential learning in action.Aldershot, Hants., UK: Gower.

Davidson, L. 2001. Qualitative research and making meaning from adventure: A case study of boys' experiences of outdoor education at school. Journal of Adventure Education and Outdoor Learning, 1(2), 11-20.

Dewey, J. 1983. Report and recommendations upon Turkish education. Dalam Jo Ann Boydston (eds.), The Middle Works: Essays on Politics and Society, 1923-1924. Carbondale: Southern Illinois Press.

Gass, M.A. 1995. Adventure family therapy: An innovative approach answering the question of lasting change with adjudicated youth. Monograph on Youth in the 1990s. Jld. 4 ms 103-117.

Gass, M. (Ed.). 1993. Adventure therapy. Dubuque, IA.: Kendall Hunt Gass, M. 1993. Adventure therapy: Therapeutic application of adventure programming. Dubuque, IA.: Kendall Hunt.

Gray, T. L., \& Perusco, D. 1993. Footprints in the sand: The value of outdoor education in the school curriculum. The ACHPER National Journal, Autumn, 17-20.

Hattie, J.A., Marsh, H.W., Neil, J.T. \& Richard, G.E. 1997. Adventure Education and Outward Bound: Out-of-class experience that has a lasting effect. Review of Educational Research.Vol. 67 pp43-87.

Hopkins, D. \& Putnam, R. 1993.Personal growth through adventure. London, England: David Fulton Publishers. 
Jurnal Ilmu Keolahragaan Vol. 17 (2), Juli-Desember 2018: 1 - 5

Kolb, D.A. 1984. Experiential Learning: Experience as the source of development. New Jersey, NJ: Prentice Hall.

Kraft, R. \& Sakofs, M. (Eds.). 1991. The theory of experiential education. Boulder, CO: Association of Experiential Education.

Lugg, A. 1999.Directions in outdoor education curriculum.Australian Journal of Outdoor Education, 4(1), 25-32.

Marsh, H.W. \& Richards, G.E. 1988. The Outward Bound Bridging Course for low achieving males: Effects on academic achievement and multidimensional selfconcepts. Australian Journal of Psychology. Vol. 40 pp 281-298

McRae, K. (Ed.) 1990. Outdoor and environmental education: Diverse purposes and practices. Melbourne, Victoria, Australia: Macmillan, pp. 1-27.

Rogers, C.R. 1985. Towards a more human science of the person.Journal of Humanistic Psychology. Vol. 25, pp 7-24

Sudjana.(1996). Metode Statistik.Bandung : Tarsito

Undang-undang No.20 tahun 2003.Sistem Pendidikan Nasional. 